\title{
The Cerebellum and Cerebellum-Like Structures of Cartilaginous Fishes
}

\author{
John C. Montgomery ${ }^{\mathrm{a}}$ David Bodznick $^{\mathrm{b}}$ Kara E. Yopak ${ }^{\mathrm{c}}$ \\ a Leigh Marine Laboratory, University of Auckland, Auckland, New Zealand; ${ }^{b}$ Department of Biology, \\ Wesleyan University, Middletown, Conn., USA; ' University of Western Australia, School of Animal Biology and \\ the UWA Oceans Institute, Crawley, W.A., Australia
}

\section{Key Words}

Brain - Medial and dorsal octavolateralis nuclei · Corpus

cerebellum · Evolution · Syngeny · Subsumption

architecture

\begin{abstract}
The cerebellum is well developed in cartilaginous fishes, with the same cell types (barring basket cells) and organizational features found in other vertebrate groups, including mammals. In particular, the lattice-like organization of cerebellar cortex (with a molecular layer of parallel fibers, interneurons, spiny Purkinje cell dendrites, and climbing fibers) is a defining characteristic. In addition to the cerebellum, cartilaginous fishes have cerebellum-like structures in the dorsolateral wall of the hindbrain. These structures are adjacent to and, in part, contiguous with the cerebellum. They are cerebellum-like in that they have a molecular layer of parallel fibers and inhibitory interneurons that has striking organizational similarities to the molecular layer of the cerebellar cortex. However, these structures also have characteristics that differ from the cerebellum. For example, cerebellum-like structures do not have climbing fibers and are clearly sensory. They receive direct afferent input from peripheral sensory receptors and relay their outputs to midbrain sensory areas. As a consequence of this close sensory association and the ability of researchers to characterize signal processing
\end{abstract}

in these structures in a behaviorally relevant context, good progress has been made in determining the fundamental processing algorithm of the cerebellum-like structures. This algorithm enables the molecular layer to act as an adaptive filter that cancels self-generated noise in electrosensory and lateral line systems. Given the fundamental similarities of the molecular layer across these structures and the phylogeny of these structures across basal vertebrates, it is clear that these structures share a common genetic-developmental program. Syngeny is a term that has been used to describe similarity of structure due to a shared genetic-developmental program, whether the structures are phylogenetically homologous or not. Given that the cerebellum and cerebellumlike structures are physically adjacent, we propose that cerebellum-like structures were the evolutionary antecedent of the cerebellum and that the cerebellum arose through a change in the genetic-developmental program, amounting to a duplication of existing structure. Such duplication to form adjacent structures can be considered a special case of syngeny. On this view, the cerebellum is an evolutionary innovation in gnathostomes that is literally superimposed on pre-existing underlying brain structures and pathways. From this perspective, the cerebellum can be considered an example of 'subsumption architecture', a term that describes the addition of modules that add computational power while maintaining existing fundamental functionality. This addition is reflected in the finding that in elasmobranchs

\section{KARGER \\ Fax +4161306 1234 \\ E-Mail karger@karger.ch}

www.karger.com
(C) 2012 S. Karger AG, Basel

0006-8977/12/0802-0152\$38.00/0

Accessible online at:

www.karger.com/bbe
John C. Montgomery

Leigh Marine Laboratory, University of Auckland

Private Bag 92019

Auckland 1142 (New Zealand)

Tel. +64 9373 7999, E-Mail j.montgomery@auckland.ac.nz 
with relatively large brains, the size of the telencephalon and cerebellum enlarge disproportionately, while those parts of the brain that contain more direct sensory and motor connections do not. Added 'computational' power in the chondrichthyan brain and the comparative function and evolution of the cerebellum and cerebellum-like structures across the cartilaginous fishes supports the idea of the cerebellum as an example of subsumption architecture.

Copyright $\odot 2012$ S. Karger AG, Basel

\section{Introduction}

Early chordate evolution is characterized by quite remarkable evolutionary innovations, especially the formation of the 'new head' in craniates, with its paired sense organs and basic brain plan [Northcutt and Gans, 1983; Depew and Olsson, 2008]. Although it has been debated whether cerebellar tissue exists in the myxinoids [Larsell, 1967; Nieuwenhuys, 1967; Ronan and Northcutt, 1998; Northcutt, 2002], it is a generally accepted view that at the juncture between vertebrates and gnathostomes (jawed vertebrates), there is an additional innovation to the central nervous system with the appearance of the cerebellum [reviewed by Striedter, 2005]. Thus, the nervous system of cartilaginous fishes represents an early, yet remarkably complete, stage in the evolution of the vertebrate brain. Understanding the structure, function, and development of the brain in early chordates, including cartilaginous fishes, and understanding the variation in brain structure within this clade, can provide insight into basic principles of brain organization and evolution. This, in turn, can inform us as to how brain evolution has both constrained and enabled vertebrate behavioral capability.

In addition to the cerebellum, cartilaginous fishes have two other cerebellum-like structures in the dorsolateral wall of the hindbrain. These are the medial and dorsal octavolateralis nuclei (MON and DON, respectively). These two structures are also found in lampreys, the sister clade to gnathostomes. However, lampreys (petromyzontids) appear to lack a true cerebellum [Larsell, 1967; Nieuwenhuys, 1967; Ronan and Northcutt, 1998; Northcutt, 2002]. This phylogenetic pattern suggests that these cerebellum-like structures could be the evolutionary antecedent for the cerebellum.

Cerebellum-like structures, in addition to the MON and DON, are found elsewhere across chordates. The similarities and differences across these structures were reviewed by Montgomery et al. [1995] and the evolution of cerebellum-like structures was reviewed by Bell [2002].
As our part of this special issue on the nervous system of cartilaginous fishes, we will focus on the current understanding of the structure and function of cerebellum and cerebellum-like structures in this clade and update the evidence relevant to the evolutionary relationships of these structures. On the basis of this evidence, we support Bell's [2002] suggestion that the source of the evolution of these structures is 'syngeny', or a shared genetic-developmental program. Given that the cerebellum and cerebellum-like structures are physically adjacent and that the cerebellum-like structures are present in the jawless vertebrates, which lack a cerebellum, we propose that cerebellum-like structures were the evolutionary antecedent of the cerebellum and, furthermore, that the cerebellum arose through a change in the genetic-developmental program, amounting to duplication of existing structure, and thus represents a special case of syngeny.

We will also review the recent progress that has been made describing and analyzing the variation in the cerebellum and cerebellum-like structures across the cartilaginous fishes [Northcutt, 1978; Yopak et al., 2007; Yopak, 2012]. How does the evolution of these structures within the clade relate to phylogenetic and ecological patterns? The evidence suggests that in chondrichthyans with relatively large brains, the size of brain areas associated with enhanced neural processing, such as the telencephalon and cerebellum, enlarge disproportionately, while those that contain more direct sensory and motor connections do not [Yopak et al., 2010a]. The view of the cerebellum as an evolutionary innovation in gnathostomes, literally superimposed on existing underlying brain structures, pathways, and circuitry is suggestive of 'subsumption architecture' [Yopak et al., 2010a], a term borrowed from computer science that describes the addition of modules that add computational power while maintaining existing fundamental functionality. This concept of subsumption architecture is also implicit in the widely held view of the cerebellum as superimposed on underlying basic circuitry [Ito, 2006].

\section{The Cerebellum and Cerebellum-Like Structures of Cartilaginous Fishes}

The gross anatomy of the elasmobranch cerebellum has been most recently reviewed by New [2001]. It sits above the junction of the midbrain and hindbrain and can be divided into the corpus cerebellum and the vestibulolateral cerebellum. Together, they make up a very significant part of the brain in cartilaginous fishes, as 


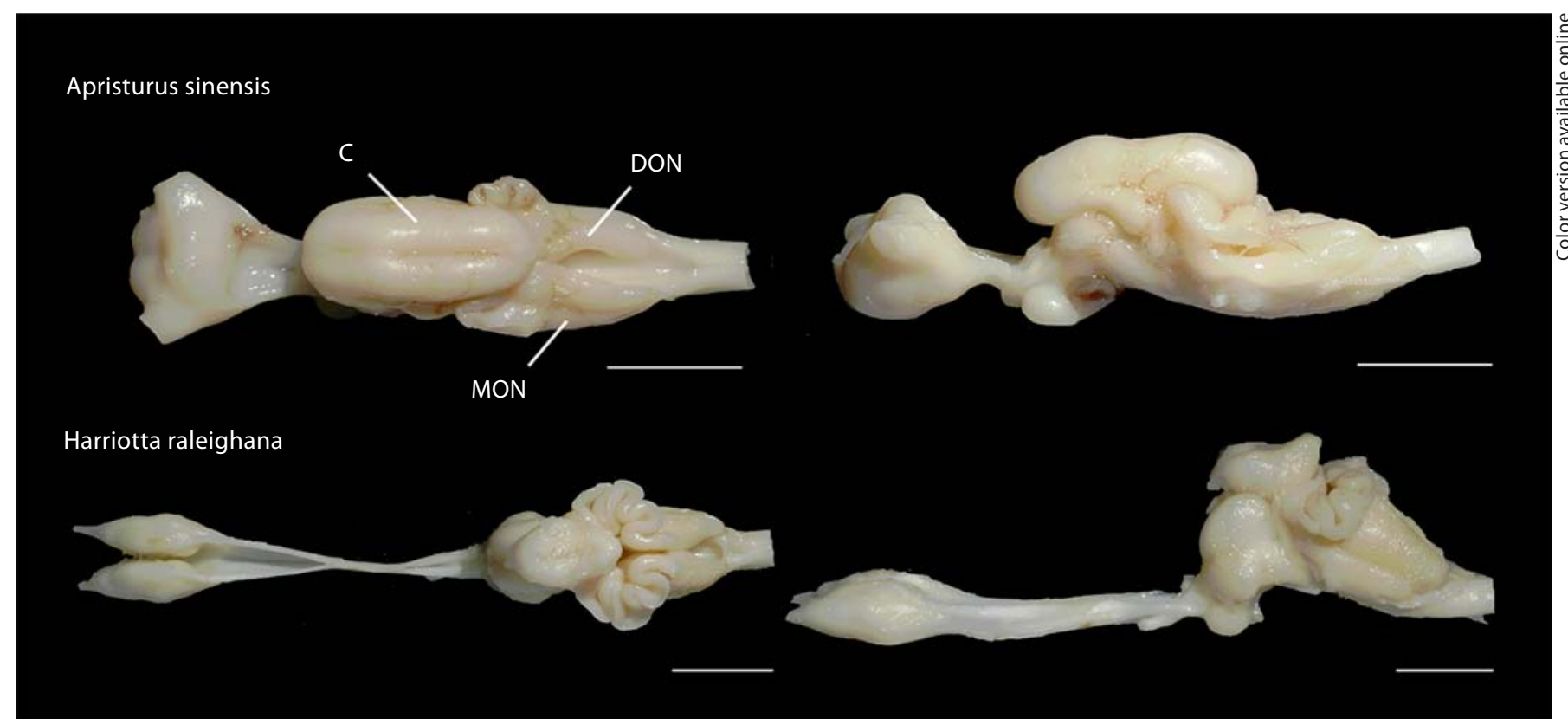

Fig. 1. Brains from two chondrichthyans, Apristurus sinensis and Harriotta raleighana, in dorsal and lateral views. $\mathrm{C}=$ Cerebellum; $\mathrm{DON}=$ dorsal octavolateralis nuclei; $\mathrm{MON}=$ medial octavolateralis nuclei (DON and MON are collectively the cerebellum-like structures). Scale bar $=1 \mathrm{~cm}$.

much as $42 \%$ of the brain in some (e.g. Apristurus sinensis (fig. 1) [Yopak and Montgomery, 2008]). The vestibulolateral cerebellum is further subdivided into a medial portion, sometimes called the 'lower lip', which is associated with the vestibular system (vestibulocerebellum; VC), and bilaterally paired lateral portions sometimes termed the 'auricles' because of their pinna-like shape in many species. The 'auricles', which are visible as folds of tissue to either side and below the posterior portion of the corpus cerebellum, join with the lower lip at one end and with the cerebellum-like structures of the hindbrain at the other end and are comprised of the granule cell populations that supply parallel fibers to the DON and MON. The cerebellum-like structures, the DON and the MON, are located on the laterodorsal wall of the hindbrain. In some species, such as Harriotta raleighana, the auricles and cerebellum-like structures are relatively very large. In this species, the MON and DON together comprise $34 \%$ of the brain (fig. 1) [Yopak and Montgomery, 2008]. Adding to this, the cerebellum, comprising $23 \%$ of the total brain weight in this species, gives a total of $57 \%$ of the brain of this animal made up by the cerebellum and cerebellum-like structures [Yopak and Montgomery, 2008]. Understanding the structure, function, development, and evolution of these components, which may make up over half the brain in some species, has the potential to contribute to fundamental questions in early vertebrate brain evolution and behavioral capabilities.

At the level of gross anatomy, it is also worth drawing attention to the very close association of the vestibulocerebellum, MON, and DON with the octavolateralis senses. As covered in more detail later, the $\mathrm{VC}$ receives strong input from the vestibular labyrinth, including both the semicircular canals and the otolith organs. The output from the VC is back to the vestibular nuclei. Vestibular information is important for a wide range of behaviors, including postural control, locomotion, and eye movement. The MON receives the afferent nerves from the mechanosensory lateral line system, and the DON receives the afferents from the electrosensory ampullae of Lorenzini. Output neurons from both the MON and the DON project to the contralateral midbrain. Interestingly, cartilaginous fishes with purported greater reliance on these non-visual octavolateralis senses have relatively enlarged MON and DON in comparison to other chondrichthyan species [Yopak et al., 2007; Yopak and Montgomery, 2008; Kajiura et al., 2010; Yopak, 2012], as described in later sections. 
Fig. 2. Schematic diagram of the organization of corpus cerebellar circuitry in chondrichthyans, with notation of afferent and efferent pathways. Filled circles indicate inhibitory synapses and open circles indicate excitatory synapses. Connectivity from New [2001].

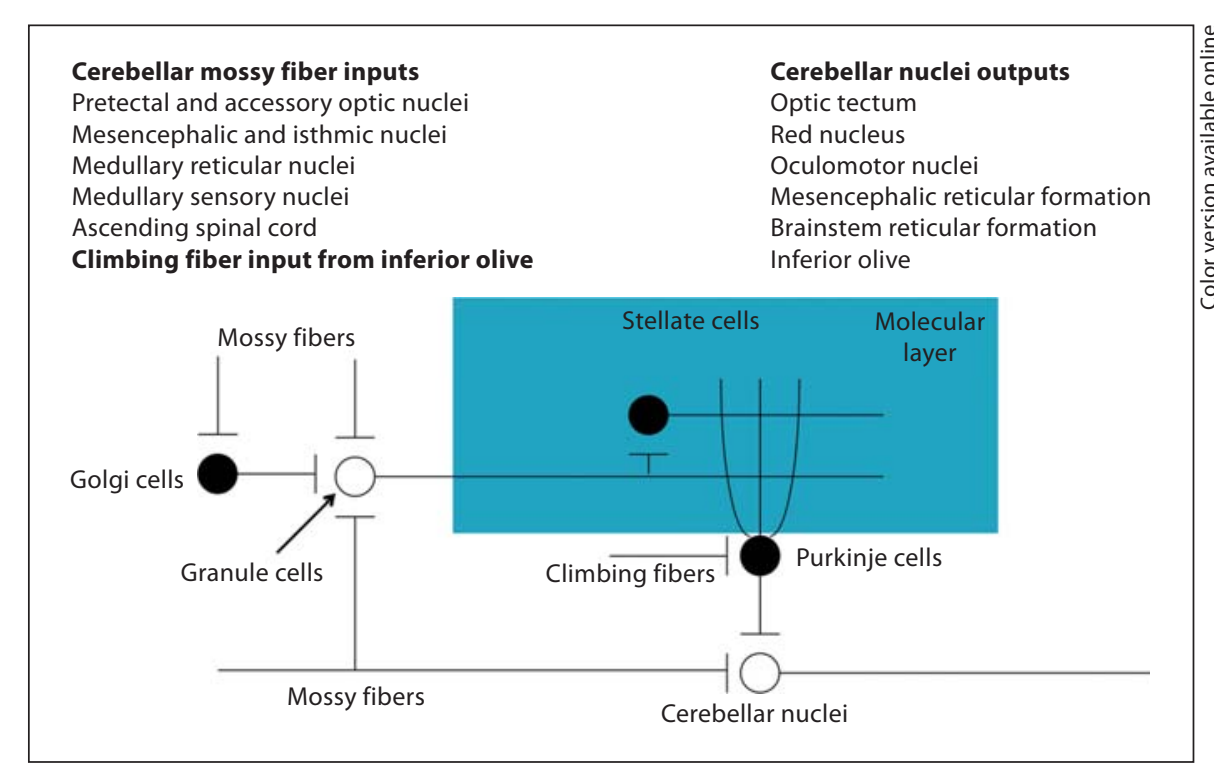

\section{The Unifying Molecular Layer}

The superficial layer of the corpus cerebellum (C) is called the molecular layer and has a distinct structure composed of a dense packing of fine, unmyelinated parallel axons that originate from granule cells (fig. 2). Stellate cell interneurons within the molecular layer and the spiny dendrites of Purkinje cells make up a lattice-like organization of cerebellar cortex. The molecular layer is a common defining characteristic of the cerebellum and cerebellumlike structures. Indeed, the MON and DON derive their 'cerebellum-like' name from the presence of a molecular layer of parallel fibers and inhibitory interneurons, which has striking organizational similarities to the molecular layer of the cerebellar cortex. However, MON and DON also have characteristics which differ from the cerebellum. For example, cerebellum-like structures do not have climbing fibers and they are clearly sensory. They receive direct afferent input from peripheral sensory receptors and relay their outputs to midbrain sensory areas. The cellular organization and connectivity of the MON, DON, VC, and C are summarized and compared in the following section.

\section{Cellular Organization and Connectivity of Cerebellum and Cerebellum-Like Structures}

The MON and the DON have largely similar organization (fig. 3). Afferent nerves from the mechanosensory lateral line and the electrosensory system segregate be-

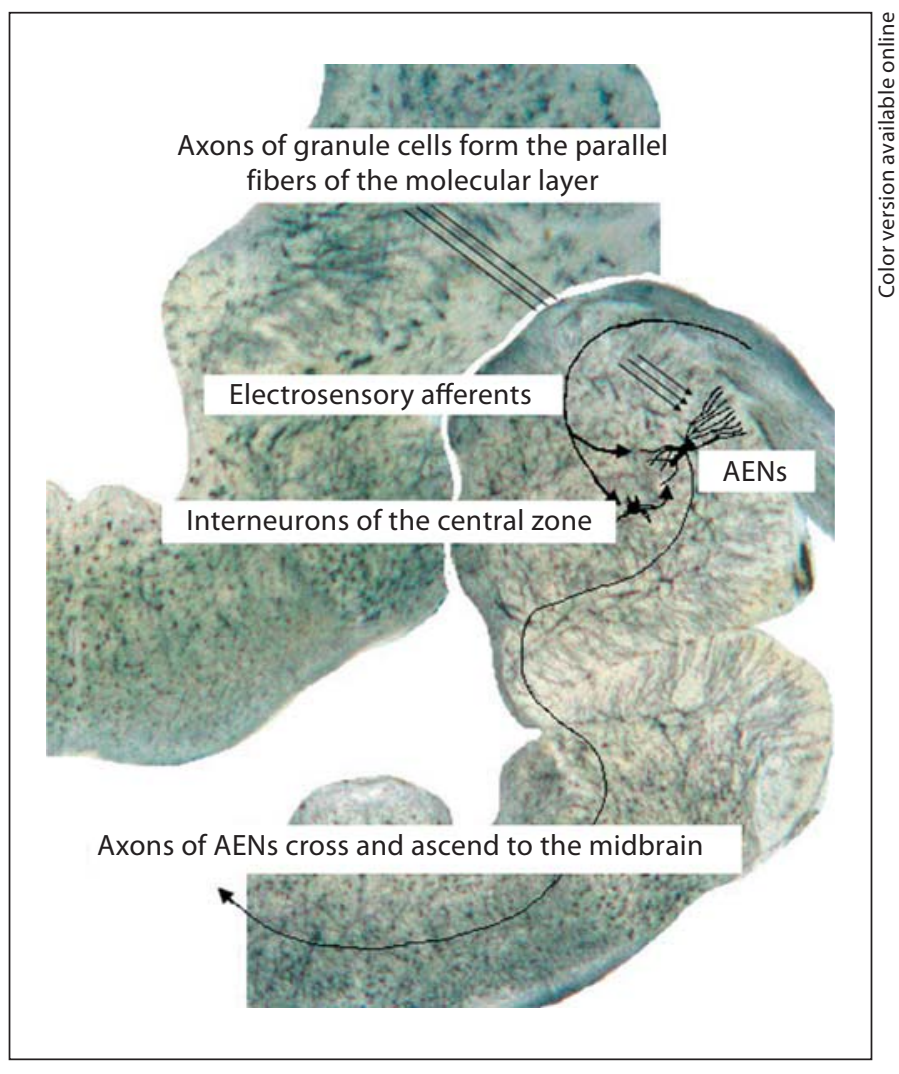

Fig. 3. Ascending efferent neurons (AENs) and circuitry of the dorsal octavolateralis nucleus (DON), overlaying Golgi-stained transverse sections of the right half of the hindbrain in the chimaerid Callorhinchus. Adapted from Montgomery and Bodznick [2010]. 
Fig. 4. A simplified diagram of the circuitry of the corpus cerebellum (C), vestibulocerebellum (VC), and medial and dorsal octavolateralis nuclei (MON/DON). The cellular organization and connectivity of the $\mathrm{C}$ is remarkably similar to that of the VC, MON, and DON, though the cerebellum is not closely connected to a particular sensory system and the principal neurons of the $\mathrm{C}$ and $\mathrm{VC}$ are Purkinje cells. In contrast, the MON and DON lack climbing fiber input and the principal cells (AENs) of the MON and DON are excitatory and not GABAergic like the Purkinje cells of the C and VC. Closed circles = inhibitory interneurons (GABAergic) and open circles = excitatory interneurons. $\mathrm{PC}=$ Purkinje cells; GC = granule cells.

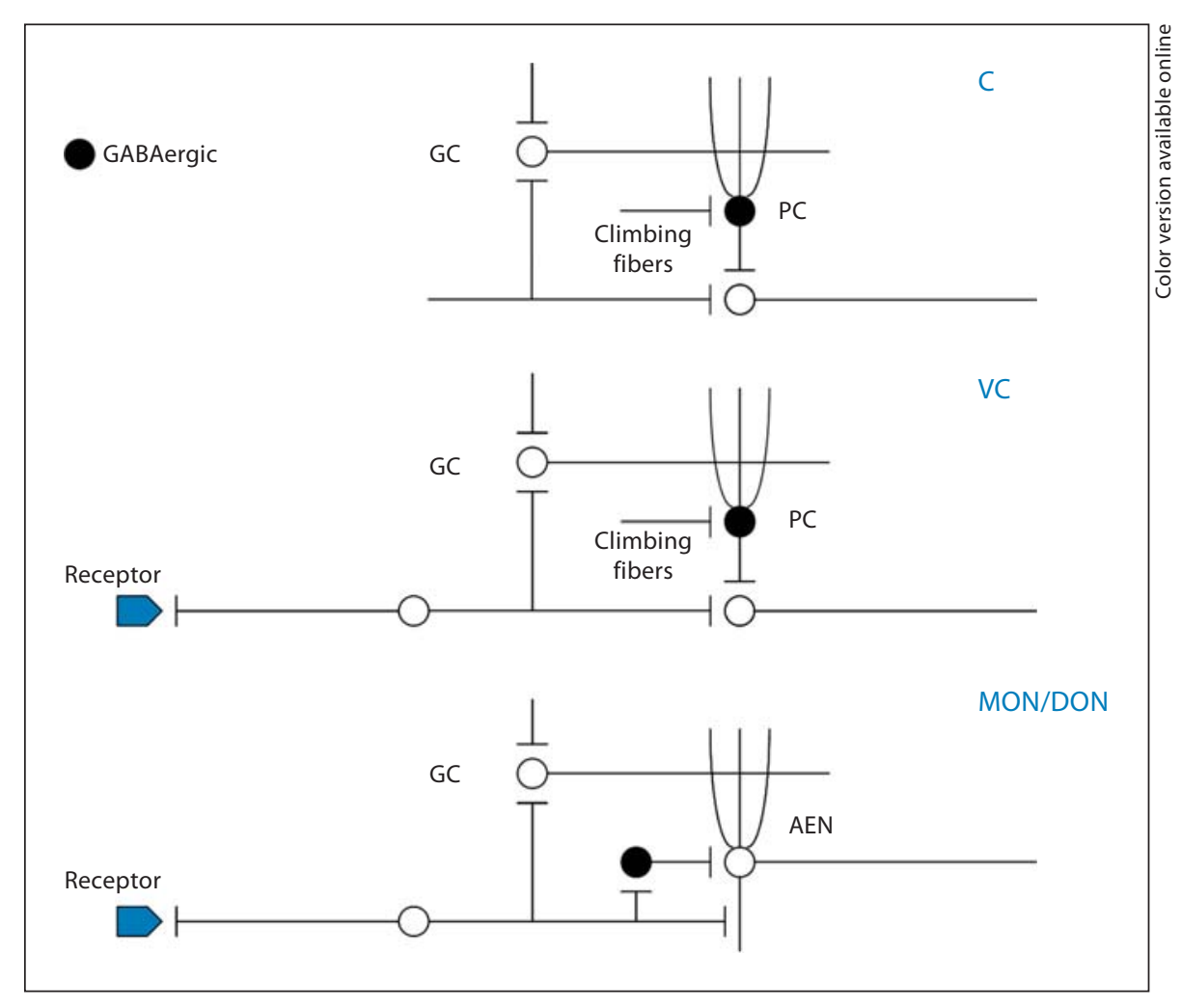

fore entering the wall of the hindbrain to go into the MON and DON, respectively [Bodznick and Northcutt, 1980]. After entering the nuclei, the afferents bifurcate to run rostral and caudal within the central neuropil, termed central zone, of the nuclei. Afferents contact the ventral dendrites of the principal cells of the nuclei (fig. 4). These neurons are called ascending efferent neurons (AENs). AENs sit below the molecular layer; they extend spiny dendrites into the molecular layer, which receive multiple inputs from parallel fibers and stellate cell axons. The axons of AENs from DON and MON leave the nuclei and cross the midline to project to the lateral and dorsomedial nuclei, respectively, of the mesencephalon. Within the central zone of the DON, there are interneurons that receive afferent input and project to adjacent and contralateral AENs. Some of these interneurons are GABAergic [Duman and Bodznick, 1997]. The parallel fibers that make up the molecular layer of the MON and DON come from sets of granule cells called the lateral granular area (for the MON) and dorsal granular ridge (for the DON). These two areas of granule cells make up the auricles. Auricular granule cells receive inputs from octavolateralis afferents, but also from many other sources.
For comparison, a simplified diagram of the cellular organization and connectivity of the DON, VC, and corpus cerebellum are shown in figure 4 . For the VC, vestibular afferents enter the hindbrain and synapse with vestibular neurons. These neurons are on the direct paths responsible for various vestibular-related behaviors, including postural control, locomotion, and eye movement. Vestibular afferents also project to the granule cells, providing the parallel fibers of the VC. The outstanding difference between the $\mathrm{VC}$ and the DON is that the principal neurons of the VC, that is, the neurons that sit below and tap into the molecular layer, are Purkinje cells. They are GABAergic and project to, and inhibit, the vestibular neurons.

The cellular organization and connectivity of the corpus cerebellum is very similar to that of the VC (fig. 2, 4). The key difference is that the corpus cerebellum is not closely aligned with or connected to a particular sensory system. Mossy fiber inputs to the granule cells come from a wide range of sources (fig. 2). In addition, the Purkinje cell output is to the deep cerebellar nuclei, which in turn project to a wide range of brain areas. The diagrams in figure 4 also show an additional input to Purkinje cells; this is known as a climbing fiber input. These axons orig- 


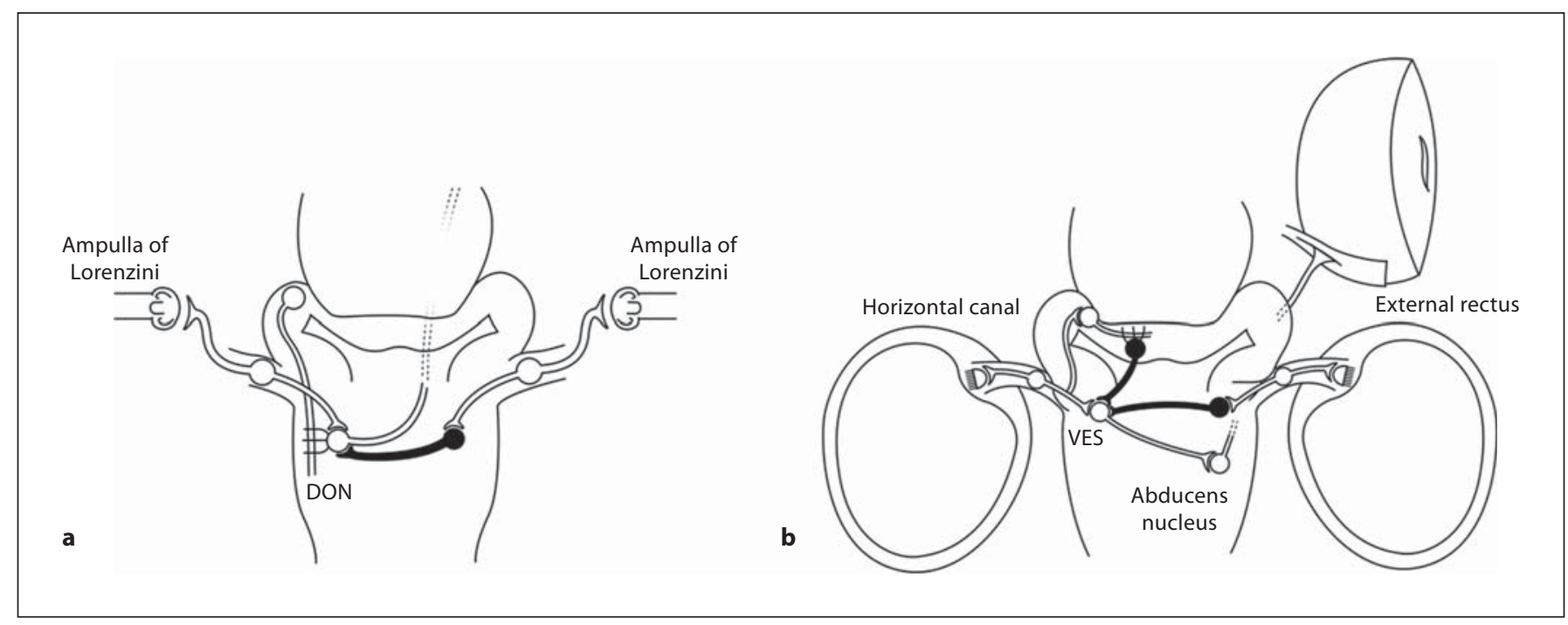

Fig. 5. A dorsal schematic of the crossed inhibitory pathway that exists in the lateral line, electrosensory, and vestibular systems of cartilaginous fishes. a Ipsilateral and contralateral inhibitions play an important part in electrosensory central processing in the DON. Self-generated inputs from the electroreceptors (ampullae of Lorenzini) are predominantly suppressed via a 'commonmode' signal rejection mechanism. These ipsilateral and contra- lateral inhibitions likely play a comparable role in the MON. b In the vestibular system, the semicircular canals form opposing pairs. The horizontal semicircular canals illustrated have opposite sign responses to any given horizontal head rotation. Increased activity on one side is matched by decreased activity on the other. inate from cells within the inferior olive (fig. 2) and form strong synapses on the cell bodies and proximal dendrites of the Purkinje cells [Schmidt and Bodznick, 1987; Alvarez-Otero et al., 1993]. Climbing fibers, or their equivalent, are not part of the wiring for MON or DON. We presume there is a climbing fiber projection to $\mathrm{VC}$ in elasmobranchs, as in other vertebrates, but this has not yet been demonstrated [Schmidt and Bodznick, 1987].

Figure 5 draws attention to a strong crossed inhibitory pathway that exists in lateral line, electrosensory, and vestibular systems. In addition to the ipsilateral inhibitory interneurons shown in figures 3 and 4, inhibitory neurons from the central zone and from areas adjacent to the molecular layer of the MON and DON send axons across the midline, which contact the contralateral AENs. Ipsilateral and contralateral inhibition plays an important part in electrosensory central processing as part of a 'common-mode' rejection mechanism (see below). These inhibitory connections presumably play an equivalent role in lateral line systems. In the vestibular system, the semicircular canals form opposing pairs. For example, the horizontal semicircular canals illustrated in the figure have opposite sign responses to any given horizontal head rotation. Increased activity on one side is matched by decreased activity on the other. Hence, crossed inhibition can play an effective role in signal to noise enhancement.

\section{Function of the Cerebellum-Like DON}

The operation of the dorsal octavolateralis nucleus (DON) as an adaptive filter was proposed by Montgomery and Bodznick [1994], reviewed in detail in Bell et al. [1997] and Bodznick et al. [1999], and nicely summarized by Devor [2000]. The cerebellum-like structure of the DON is illustrated in figures 3 and 4, which emphasize the parallel fiber molecular layer and spiny molecular layer dendrites of the principal neurons (AENs). Also shown is the electrosensory input onto the ventral dendrites of the AENs, both direct and indirect via inhibitory interneurons. The AENs project to the contralateral midbrain. Afferent electrosensory input to the DON has been shown to be strongly modulated by self-generated electric fields, whereas the AEN activity is not. Much of the cancellation of self-generated fields is done by the inhibitory interneurons. Self-generated fields are 'common-mode' to many of the receptors, and the AENs have been shown to have 
Fig. 6. The adaptive filter response in the cerebellum-like hindbrain of the little skate, Raja erinacea. Each trace is a peristimulus time histogram of AEN spiking. Top trace ventilatory movement record from which the peristimulus histograms of spike activity were triggered. a Prestimulation. The peristimulus histograms (top to bottom) show AEN's low spike activity with no response to ventilation. b The strong response to an electrical dipole stimulus, coupled to ventilation, decreasing over a 10-min period, followed by (c) a strong negative sensory image after the stimulus is withdrawn that was extinguished over the subsequent $10 \mathrm{~min}$. Each trace $2 \mathrm{~s}$ duration. Vertical calibration 10 spikes/s. Data from Montgomery and Bodznick [1994] and image adapted from Montgomery and Bodznick [2010].

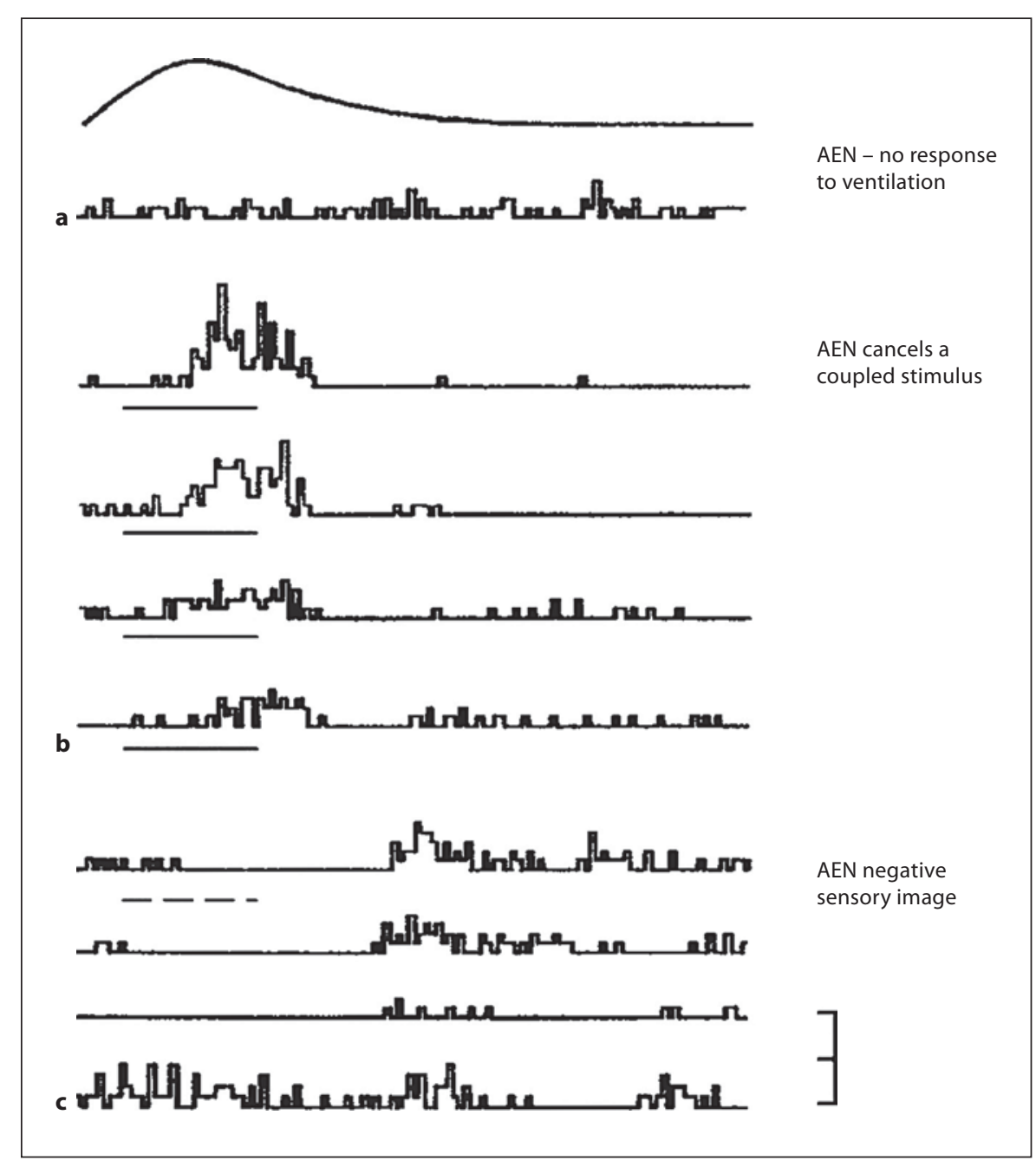

a focal excitatory receptive field and a diffuse inhibitory surround. This receptive field organization generated by the direct afferent input and indirect input through the inhibitory interneurons provides the mechanism for 'common-mode suppression' of self-generated fields [Montgomery, 1984; Bodznick and Montgomery, 1992; Bodznick et al., 1992; Montgomery and Bodznick, 1993]. In addition, the molecular layer organization provides for an adaptive filter to cancel remaining self-generated noise. Figure 6 illustrates the experimental demonstration of the adaptive cancellation of sensory input, coupled to the animal's own activity. The stimulus coupled to ventilation initially generates a strong excitation followed by a suppression of activity. Both effects decline with time. When the sensory stimulus is switched off, a negative sensory image is apparent, with inhibition occurring where the cell was previously driven by the stimulus and excitation where it was inhibited. The mechanism for the generation of the negative image is parallel fiber/AEN long-term depression (LTD), driven by spike activity of the AEN. The two learning rules are: if the AEN is active, turn down the gain of coincidently active parallel fiber synapses; conversely, if parallel fiber synapses are active in the absence of AEN firing, then increase the strength of their connection. These rules have been directly demonstrated in mormyrid cerebellum-like structures [Han et al., 2000] and more recently in the DON [Bertetto, 2007]. The functional principles established in the DON have also been seen in other systems, such as the mormyrid electric fish and the gymnotiform fish, which also cancel reafferent input through a negative image of expected sensory information [Bell, 1982; Bell and Szabo, 1986; Bastian, 1995; Bell et al., 1997]. These rules drive the formation of an internal model of the predicted sensory 
reafference, generated by the animal's own activity. The time-varying information in the parallel fibers, that is likely to be of most utility in the formation of the model of predicted reafference associated with ventilation, are efference copy signals from ventilatory motor centers and proprioceptive input associated with breathing.

In conclusion, there is good experimental evidence that the function of the cerebellum-like organization of the DON is to provide an adaptive filter to cancel selfgenerated noise and good reason to believe that this is realized by parallel fiber/AEN plasticity driven by AEN activity.

\section{Function of MON, VC, and Cerebellum in Cartilaginous Fishes}

The detailed function of the MON, VC, and cerebellum in cartilaginous fishes is less well known than that of the DON. Work on the MON provides strong evidence that its function is analogous to that of DON [Perks, 2007]. Like the electrosensory system, mechanosensory lateral line sensory systems are also prone to self-generated noise. The inhibitory circuits in the MON likely effect the removal of common-mode noise, and MON AENs have recently been shown to adaptively cancel lateral line sensory input coupled to the animal's own activity.

The wiring of the vestibulocerebellum in cartilaginous fishes (fig. 4) is comparable to VC circuitry found in other fishes [Montgomery, 1982; Puzdrowski and Leonard, 1994]. However, there have been few functional studies of vestibular reflexes [Montgomery, 1983; Timerick et al., 1990] and VC [Montgomery, 1980] in cartilaginous fishes. In contrast, goldfish have been a model system for the study of vestibulo-ocular reflexes and adaptive gain control. In goldfish and other vertebrates, the vestibuloocular reflex (VOR) has been one of the mainstay models for the study of cerebellar function and plasticity. The utility of the model derives from the precise nature of eye movement control and the rather direct sensory/motor connectivity with the role of the deep cerebellar nuclei taken by the vestibular nuclei. As an open-loop reflex, precise gain control is essential for accurate function. Imprecise function is signaled by image slip on the retina and conveyed to cerebellar cortex by the climbing fibers. Experiments using adaptive calibration of the VOR have indicated plasticity in both cerebellar cortex and the brainstem [Boyden et al., 2004] and modeling studies suggest that information originally learned in the cerebellar cortex can be transferred and expressed in the brainstem [Porrill and Dean, 2007]. The presumption is that the VC in cartilaginous fishes shows the same adaptive calibration of vestibular reflexes, but this has yet to be directly tested.

Physiological and functional studies of the cerebellum in Chondrichthyes have been reviewed by New [2001]. Experimental studies of cerebellar function in this clade are sparse and the ideas on what the cerebellum does and how it does it are largely speculative. Roles have been suggested for the cerebellum in modulation of the reticularformation inhibition of spinal cord reflexes [Paul and Roberts, 1979] and in modulation of spinal locomotory pattern generators [Paul and Roberts, 1984]. More recently, Montgomery and Bodznick [2010] have reviewed the functional similarities between the cerebellum and the DON. Their review emphasizes the morphological similarities of the molecular layer across the DON and cerebellum and proposes that this morphological similarity is matched by a common functional algorithm across these structures. Cerebellar model systems across a wide range of vertebrates are shown to be consistent with this proposal; however, it is also noted that experimental evidence for this type of functionality in chondrichthyan fishes does not exist. It is also argued that the presence of this neural processing algorithm does not directly translate to function, in the sense that to understand what the cerebellum actually does, we also need more complete descriptions of the output connectivity of the cerebellum, particularly in the less-studied groups such as the cartilaginous fishes.

\section{Evolution of the Cerebellum from a Cerebellum-Like Precursor}

Bell et al. [2008] drew attention to the fact that the cerebellum-like structures of the hindbrain existed in vertebrate phylogeny prior to the cerebellum. The medial octaovolateralis nucleus (MON) is evident in some hagfish (myxinoids), and both MON and DON occur in lampreys. Though a subject of debate [Larsell, 1967; Nieuwenhuys, 1967], a true corpus cerebellum, vestibulocerebellum, and Purkinje cells are absent from both these groups [Weigle and Northcutt, 1998]. However a thin band of cells located medially to the MON has been identified in jawless fishes [Ronan and Northcutt, 1998; Weigle and Northcutt, 1998]. One plausible evolutionary/developmental scenario is that the developmental program responsible for the original MON-like structure can undergo change, which results in duplication. 
An adjacent duplication of structure could explain the evolutionary advent of the DON from the MON, the VC from the DON, and the corpus cerebellum from the VC (fig. 7).

One complication with this evolutionary/developmental scenario is evident in figure 4 . The principal cells (AENs) of the DON are excitatory and certainly not GABAergic like the Purkinje cells of the VC. One possibility is that, in the transition from DON to VC, some of the GABAergic interneurons of the DON (especially the ones adjacent to the molecular layer) may have displaced the AENs as the 'principal' neurons, becoming the new Purkinje cells. The plausibility of the interneurons tapping into the molecular layer is supported by the inhibitory interneurons of the electrosensory lateral line lobe (ELL) in mormyrids, which have spiny molecular layer dendrites [Bell et al., 2008].

Further comparative evidence for this evolutionary/ developmental possibility comes from the loss of electroreception and the DON in most bony fishes (fig. 7). Electroreception has been evolutionarily reinvented on two separate occasions, with perhaps a developmental duplication event providing the basis for the cerebellum-like ELL of weakly electric fishes. In both lineages of weakly electric fishes, the ELL again shows evidence of duplication, with multiple sensory maps of the body surface. Interestingly, in adjacent maps, the somatotopy is reversed. Within cerebellar corpus phylogeny, the teleost valvula, and the mammalian neocerebellum may lie further examples of this propensity for developmental duplication.

Bell [2002] and Bell et al. [2008] use the strong crossvertebrate similarities in a wide range of cerebellum-like structures, some of which are adjacent and some of which are not, to argue that these structures have a shared genetic-developmental program. The term 'syngeny' was coined by Butler and Saidel [2000] to describe the relationship of a given character in different taxa that is produced by shared generative pathways. They also explicitly include recognizably corresponding characters that occur as a repeated unit within an individual that has (or is hypothesized to have) a shared generative basis, regardless of the phylogenetic distribution of the character. The change in a developmental program that results in duplication of one structure to form two similar adjacent structures can be considered a special case of syngeny.

Interestingly, the phylogeny of the vestibular system shows a similar duplication (fig. 8). Hagfish have a single semicircular canal with two sensory cristae. Lampreys have two semicircular canals, each with a crista. Carti-

\begin{tabular}{|c|c|c|c|}
\hline & MON & DON & VC/C \\
\hline Euteleostei & MON + ELL & & \\
\hline Elasmobranchii & & & \\
\hline Holocephali & & & \\
\hline Lampetra & & & \\
\hline Eptatretidae & & & \\
\hline
\end{tabular}

Fig. 7. Proposed evolution of cerebellum-like structures, indicating that through early vertebrate evolution, the MON may have given rise to the $\mathrm{DON}$, the $\mathrm{DON}$ to the $\mathrm{VC}$, and the $\mathrm{VC}$ to the $\mathrm{C}$ through duplication of structure as a special case of syngeny. Syngeny = Similarity of structure due to shared genetic-developmental program, whether phygenetically homologous or not. Grey squares indicate presence of structure (or homologue), white indicates absence of structure. After Bell [2002].

laginous fishes have the full complement of three semicircular canals, with the horizontal canal appearing to have come from a duplication of the anterior vertical canal. The genetic/developmental changes associated with these duplications may not be too complicated, as it has been shown experimentally that simple Otx1 knockdown in zebrafish gives rise to lamprey-like inner ears, and Otx1-/- mice show a similar lamprey-like phenotype [Hammond and Whitfield, 2006]. A role for the Otx transcription factor in cerebellar development is also indicated by ectopic cerebellar tissue that develops in the midbrain and forebrain of a mouse embryo with a genome that is Otx1+/- and Otx2+/- [Acampora et al., 1997].

An independent line of evidence for the evolution of the corpus cerebellum from a cerebellum-like hindbrain precursor is the developmental origins of mammalian cerebellar neurons in the rhombic lip and their subsequent migration to form both the deep cerebellar nuclei and the cerebellar corpus [Wang et al., 2005; Machold and Fishell, 2005]. In other words, perhaps as Murakamia et al. [2005] conclude: 'cerebellum has been brought about as an evolutionary innovation in gnathostomes, based on exaptation of $\mathrm{MBH}$ (midbrain hindbrain boundary), rhombic lip, and some regulatory gene expression already present in the vertebrate common ancestor'. 


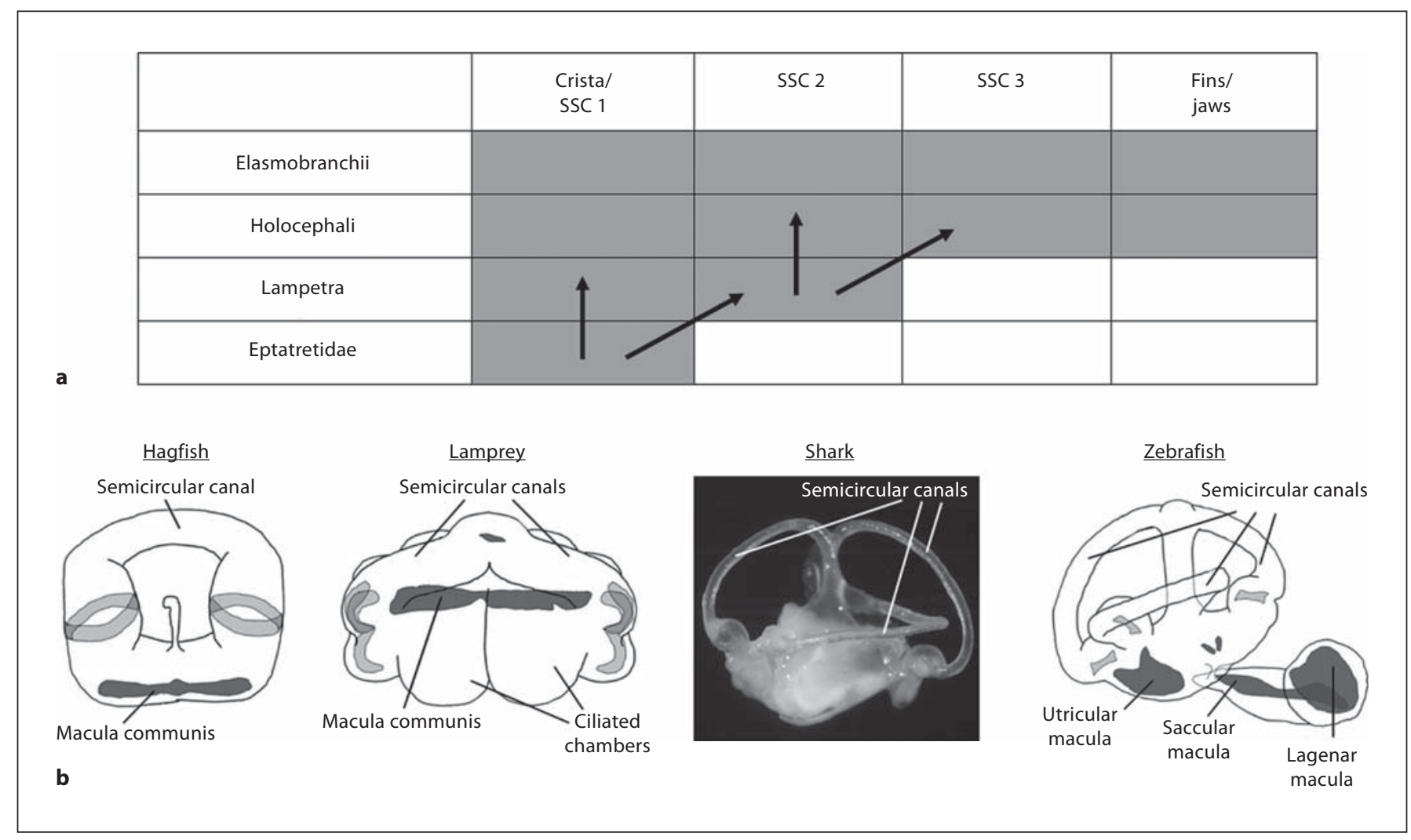

Fig. 8. a Evolution of the semicircular canals (SSC) in early vertebrates. Hagfish (Eptatretidae) have a single semicircular canal with two sensory cristae. Even if this is a derived condition [Hammond and Whitfield, 2006], it serves to illustrate a possible early condition in the evolution of SSCs. Lampreys (Lampetra) have two semicircular canals, each with a crista, and cartilaginous fishes (Elasmobranchii and Holocephali) have the full complement of three semicircular canals. Jaws and paired fins have been included in this figure to show their origins in gnathostomes, simultaneous with the 3rd semicircular canal and corpus cerebellum (see fig. 7). Grey squares indicate presence of structure (or homologue), white indicates absence of structure. $\mathbf{b}$ Comparative sketch of adult hagfish, lamprey, shark, and zebrafish inner ears. Lateral views with anterior to the left. Not to scale. Hagfish, lamprey, and zebrafish diagrams adapted with permission from Hammond and Whitfield [2006].

\section{Quantitative Evolution of Cerebellum and Cerebellum-Like Structures within Cartilaginous Fishes}

Limited data are available on variation in chondrichthyan brain organization and the implications this variation has for evolutionary adaptations in sensorimotor function in the vertebrate nervous system [Bauchot et al., 1976; Graeber, 1978; Northcutt, 1977]. Currently, the primary literature contains brain-body data on approximately $16 \%$ of all known chondrichthyan species, and even fewer data on the development of major brain regions [reviewed by Yopak, 2012]. Analyses of brain-body scaling have demonstrated that chondrichthyans have relative brain sizes that are comparable to birds and mammals [Northcutt, 1977; Myagkov, 1991; Striedter, 2005; Yopak et al., 2007, 2010a] and that cartilaginous fishes possess larger brains than teleosts of similar body size [Striedter, 2005]. Larger relative brain sizes are correlated with habitat, lifestyle, and cognitive capabilities in virtually all vertebrate groups [Budeau and Verts, 1986; Kotrschal et al., 1998; Striedter, 2005; Pollen et al., 2007; Shumway, 2010], including sharks [Bauchot et al., 1976; Northcutt, 1977, 1978; Yopak et al., 2007; Yopak and Montgomery, 2008; Yopak and Frank, 2009], rays and skates [Lisney et al., 2008], and holocephalans [Northcutt, 1978; Yopak et al., 2007; Yopak and Montgomery, 2008]. Quantitative studies of brain organization in chondrichthyans have demonstrated significant interspecific variation of individual brain regions. Brain patterns are simi- 
lar in species that share certain lifestyle characteristics, such as habitat, locomotory mode, and cognitive capabilities [Northcutt, 1977, 1978; Yopak et al., 2007; Lisney et al., 2008] as documented also in teleosts [Bauchot et al., 1977; Kotrschal et al., 1998], birds [Bennet and Harvey, 1985; Lefebvre et al., 1997; Hunt et al., 2001], and mammals [Eisenberg and Wilson, 1978; Clutton-Brock and Harvey, 1980; Bennet and Harvey, 1985; Harvey and Krebs, 1990; Hutcheon et al., 2002].

In both chondrichthyans and mammals, major brain areas most reliably associated with behavioral and motor complexity (e.g. telencephalon and cerebellum) enlarge disproportionately as brain size increases, while those that contain primary sensory and motor neurons do not (fig. 9) [Yopak et al., 2010a]. Cerebellum size is highly variable across this clade, and enlargement of this structure has been linked to habitat dimensionality, speed/maneuverability, proprioception, and possibly sensory acquisition [Northcutt, 1978; New, 2001; Yopak et al., 2007; Lisney et al., 2008; Yopak and Frank, 2009]. In addition to variation in size, the surface of the cerebellar corpus varies greatly in its degree of folding (termed foliation) [Yopak et al., 2007; Lisney et al., 2008]. Foliation has been suggested to be an identifying feature of highly encephalized brains in chondrichthyans [Yopak et al., 2010a] and an increased cerebellar surface area (via an increase in cerebellar foliation) may allow for more specific representations of sensory and motor components from the body surface, as in the mammalian cortex [Carlson, 1991; Yopak et al., 2010a]. Particularly higher levels of foliation are documented in animals that spend the majority of time in complex habitats or open water, such as carcharinids, lamnids, rhincotondids, sphyrnids [Yopak et al., 2007; Yopak and Frank, 2009], dasyatids, and myliobatids [Lisney et al., 2008; Ari, 2011]. Survival in these primary habitats may necessitate higher cognitive function and multi-model integration required for behaviors such as long-distance migration, vertical migration, more complex social interactions, and/or a more complex motor repertoire required when capturing agile prey.

It is well documented that morphological adaptations and sensory specializations are highly correlated with the development of the neural substratum that modulates that modality in vertebrates [Morita and Finger, 1985; Heiligenberg, 1987; Kanwal and Caprio, 1987; Finger, 1988; Kotrschal et al., 1990; Meek and Nieuwenhuys, 1998]. In cartilaginous fishes, enlargement of the cerebellum-like structures has been documented in species occurring primarily at bathyal depths [Yopak and Montgomery, 2008; Kajiura et al., 2010; Yopak et al., 2010b],

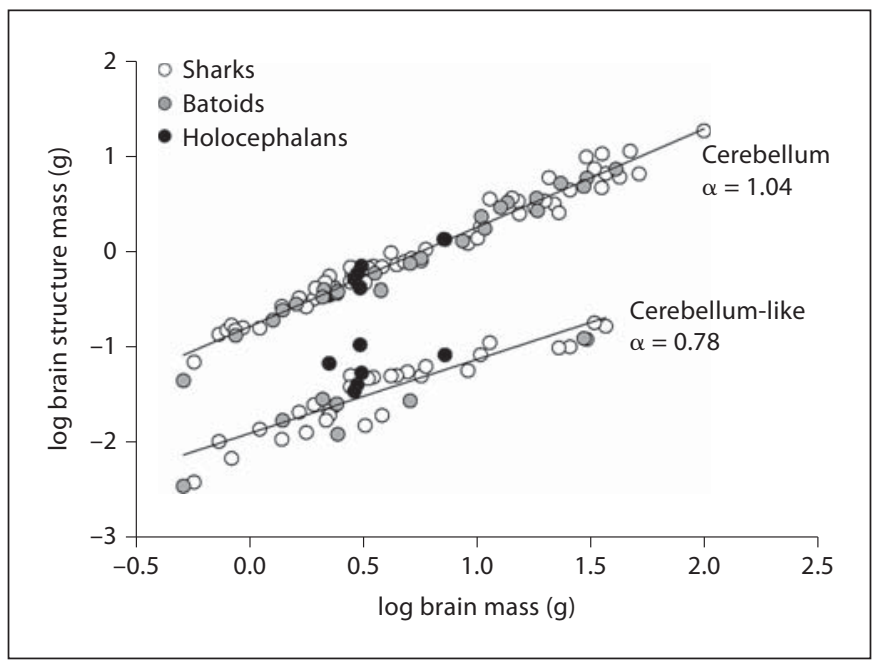

Fig. 9. Scaling of the cerebellum $(\mathrm{n}=84)$ and cerebellum-like structures $(\mathrm{n}=45)$ with brain mass in sharks, batoids, and holocephalans. The cerebellum scales hyperallometrically to the rest of the brain, while the cerebellum-like structures do not. Data from Yopak et al. [2007], Yopak and Montgomery [2008], Lisney et al. [2008], Kajiura et al. [2010], and Yopak et al. [2010a].

most noticeably in the holocephalans (fig. 9). This neuromorphological pattern has been attributed to a number of factors, including specialization of the octavolateralis senses [Yopak and Montgomery, 2008], somatotopic mapping of subdermal electroreceptors [Yopak and Montgomery, 2008; Kajiura et al., 2010], which extend down the elongated rostrum of deep sea sharks and holocephalans, and an increased selection pressure for sensitivity to novel stimuli via sensory adaptive filtering in prey-poor and conspecific-poor deep sea environments [for review, see Yopak, 2012].

\section{Subsumption Architecture}

A parallel can be drawn between neural architectures and autonomous robot design, based on the idea of 'subsumption architecture' [Yopak et al., 2010a]. This describes a system architecture used in behavior-based robotics and layered 'intelligence' behavior modules [Brooks, 1986, 1991; Hawes et al., 2007]. From the perspective of evolutionary neuroscience, the general principles arising from this literature are that more basal neural 'layers' moderate fundamental functionality and fastacting reflexes, while higher components are responsible for more complex oversight and capability. Each layer im- 
plements a particular goal of the agent, and higher layers are increasingly abstract, subsuming that of the underlying layers. In contrast to more traditional artificial intelligence approaches, each layer should function simultaneously with other layers in a bottom-up approach, with lower level reflexes taking behavioral priority, and higher layers providing added functionality, and maintaining adaptive oversight of lower-level function.

Yopak et al. [2010a] suggested that some evolutionary characteristics of the chondrichthyan brain (and indeed the mammalian brain) are similar to that of an evolvable subsumption architecture. As brains increase in size across cartilaginous fishes, they are more highly comprised of neural components associated with enhanced neural processing (e.g. telencephalon and cerebellum) as compared to other neural areas, such as the diencephalon, mesencephalon (comprised of optic tectum, torus semicircularis, and tegmentum [Hofmann, 1999]), cerebellum-like structures, and other medullary components, which moderate fundamental reflexes, sensory information processing, and physiological responses. The added size of more complex cerebellar and telencephalic 'layers' on top of these other basal components does not compromise fundamental functionality, as they remain operational, but adds behavioral complexity in more highly encephalized chondrichthyan species. The comparative function and evolution of the cerebellum (higher layer) and cerebellum-like structures (lower layer) across the cartilaginous fishes supports the idea of the cerebellum as an example of subsumption architecture.

\section{Conclusions: Syngeny and Subsumption}

Syngeny can be considered as a precursor to subsumption. If, as we argue, the cerebellum evolved from cerebellum-like structures via a developmental duplication, the formation of this added neural capacity provides the possibility of subsumption neural architecture. In a sense, this is somewhat analogous to gene duplication, where the additional gene copy then becomes available as a substrate for the evolution of new function. However, the difference with subsumption is that this new function is an added layer of functional complexity. On this scenario, the cerebellum is an evolutionary advancement in gnathostomes that is literally superimposed on pre-existing underlying brain structures and pathways and has paved the way for some aspects of higher neural function and complexity in the evolution of vertebrate brains.

\section{Acknowledgements}

The authors would like to thank Brain, Behavior and Evolution and Karger Publishers for the opportunity to contribute to this Special Issue and support for J.C.M. to attend the 2011 Karger Workshop. This paper was funded by an NSF grant and funds from Wesleyan University to D.B. and the Sir Keith Murdoch Fellowship from the American Australian Association to K.E.Y. K.E.Y. also gratefully acknowledges funds from S.P. Collin during the writing of this manuscript.

\section{References}

Acampora D, Avantaggiato V, Tuorto F, Simeone A (1997): Genetic control of brain morphogenesis through Otx gene dosage requirement. Development 124:3639-3650.

-Alvarez-Otero R, Regueira SD, Anadon R (1993): New structural aspects of the synaptic contacts on Purkinje cells in an elasmobranch cerebellum. J Anat 182:13-21.

-Ari C (2011): Encephalization and brain organization of mobulid rays (Myliobatiformes, Elasmobranchii) with ecological perspectives. Open Anat J 3:1-13.

Bastian J (1995): Pyramidal cell plasticity in weakly electric fish: a mechanism for attenuating responses to reafferent electrosensory inputs. J Comp Phys A 176:63-78

Bauchot R, Platel R, Ridet JM (1976): Brain-body weight relationships in Selachii. Copeia 2: 305-310.
Bauchot R, Bauchot ML, Platel R, Ridet JM (1977): The brains of Hawaiian tropical fishes: brain size and evolution. Copeia 1 : 42-46.

Bell CC (1982): Properties of a modifiable efference copy in an electric fish. J Neurophys 47 : 1043-1056.

Bell CC, Szabo T (1986): Electroreception: Behavior anatomy and physiology; in Bullock $\mathrm{TH}$, Heiligenberg W (eds): Electroreception. New York, John Wiley, pp 577-612.

Bell C, Bodznick D, Montgomery J, Bastian J (1997): The generation and subtraction of sensory expectations within cerebellar-like structures. Brain Behav Evol 50:17-31.

-Bell CC (2002): Evolution of cerebellum-like structures. Brain Behav Evol 59:312-326.

Bell CC, Han V, Sawtell NB (2008): Cerebellumlike structures and their implications for cerebellar function. Ann Rev Neurosci 11:1-24.
Bennet PM, Harvey PH (1985): Brain size, development and metabolism in birds and mammals. J Zool 207:491-509.

Bertetto LD (2007): Functional synaptic plasticity in the electrosensory system of the little skate Raja erninacea; PhD thesis, Wesleyan University, p 124.

Bodznick D, Northcutt RG (1980): Segregation of electro- and mechanoreceptive inputs to the elasmobranch medulla. Brain Res 195: 313-321.

Bodznick D, Montgomery JC (1992): Suppression of ventilatory reafference in the elasmobranch electrosensory system: medullary neuron receptive fields support a common mode rejection mechanism. J Exp Biol 171: 127-137. 
-Bodznick D, Montgomery JC, Bradley DJ (1992): Suppression of common mode signals within the electrosensory system of the little skate, Raja erinacea. J Exp Biol 171:107-125.

Bodznick D, Montgomery JC, Carey M (1999): Adaptive mechanisms in the elasmobranch hindbrain. J Exp Biol 22:1357-1364.

-Brooks R (1986): A robust layered control system for a mobile robot. IEEE J Robot Autom 2: $14-23$.

Brooks RA (1991): Intelligence without representation. Art Intell 47:139-159.

Boyden ES, Katoh A, Raymond JL (2004): Cerebellum-dependent learning: the role of multiple plasticity mechanisms. Ann Rev Neurosci 27:581-609.

- Budeau DA, Verts BJ (1986): Relative brain size and structural complexity of habitats of chipmunks. J Mammalogy 67:579-581.

- Butler A, Saidel W (2000): Defining sameness: historical, biological, and generative homology. BioEssays 22:846-853.

Carlson M (1991): Ontogenetic and phylogenetic perspectives on somatic sensory cortex and tactile function; in Franzen O, Westman J (eds): Information Processing in the Somatosensory System. Hampshire, Macmillan Press, pp 177-192.

-Clutton-Brock TH, Harvey PH (1980): Primates, brains, and ecology. J Zool 190:309-323.

Depew MJ, Olsson L (2008): Symposium on the evolution and development of the vertebrate head. J Exp Zool 310B:287-293.

Devor A (2000): Is the cerebellum like cerebellar-like structures? Brain Res Rev 34:149156.

Duman CH, Bodznick D (1997): Distinct but overlapping populations of commissural and GABAergic neurons in the dorsal nucleus of the little skate, Raja erinacea. Brain Behav Evol 49:99-109.

-Eisenberg JF, Wilson DE (1978): Relative brain size and feeding strategies in the Chiroptera. Evolution 32:740-751.

- Finger TE (1988): Sensorimotor mapping and oropharyngeal reflexes in goldfish, Carassius auratus. Brain Behav Evol 31:17-24.

Graeber RC (1978): Behavioral studies correlated with central nervous system integration of vision in sharks; in Hodgson ES, Mathewson RF (eds): Sensory Biology of Sharks, Skates, and Rays. Washington, US Government Printing Office, pp 195-225.

Hammond KL, Whitfield TT (2006): The developing lamprey ear closely resembles the zebrafish otic vesicle: Otx1 expression can account for all major patterning differences. Development 133:1347-1357.

-Han VZ, Grant K, Bell CC (2000): Reversible associative depression and nonassociative potentiation at a parallel fiber synapse. Neuron 27:611-622.

-Harvey PJ, Krebs JR (1990): Comparing brains. Science 249:140-146.
Hawes N, Sloman A, Wyatt J, Zillich M, Jacobsson A, Kruijff G, Brenner M, Berginc G, Skocaj D (2007): Towards an integrated robot with multiple cognitive functions. Proc AAAI 7:1-6.

-Heiligenberg W (1987): Central processing of sensory information in electric fish. J Comp Physiol 161:621-631.

Hofmann MH (1999): Nervous system; in Hamlet WC (ed): Sharks, Skates, and Rays: The Biology of Elasmobranch Fishes. Baltimore, Johns Hopkins University Press, pp 273-299.

Hunt GR, Corballis MC, Gray RD (2001): Laterality in tool manufacture by crows. Nature 414:707.

Hutcheon JM, Kirsch JW, Garland T Jr (2002): A comparative analysis of brain size in relation to foraging ecology and phylogeny in the Chiroptera. Brain Behav Evol 60:165-180.

Ito M (2006): Cerebellar circuitry as a neuronal machine. Progr Neurobiol 78:272-303.

Kajiura SM, Cornett AD, Yopak KE (2010): Sensory adaptations to the environment: Electroreceptors as a case study; in Carrier JC, Musick JA, Heithaus MR (eds): Sharks and Their Relatives. II. Biodiversity, Adaptive Physiology, and Conservation. New York, CRC Press, pp 393-433.

Kanwal JS, Caprio J (1987): Central projections of the glossopharyngeal and vagal nerves in the channel catfish, Ictalurus punctatus: clues to differential processing of visceral inputs. J Comp Neurol 264:216-230.

Kotrschal K, van Staaden MJ, Huber R (1998): Fish brains: evolution and environmental relationships. Rev Fish Biol Fish 8:373-408.

Kotrschal K, Brandstätter R, Gomahr A, Junger H, Palzenberger M, Zaunreiter Z (1990): Brain and sensory systems; in Winfield J, Nelson JS (eds): The Biology of Cyprinids. London, Chapman \& Hall, pp 284-331.

Larsell O (1967): The Comparative Anatomy and Histology of the Cerebellum from Myxinoids Through Birds. Minneapolis, University of Minnesota Press.

Lefebvre L, Gaxiola A, Dawson S, Timmermans S, Rosza L, Kabai P (1997): Feeding innovations and forebrain size in Australasian birds. Behaviour 135:1077-1097.

Lisney TJ, Yopak KE, Montgomery JC, Collin SP (2008): Variation in brain organization and cerebellar foliation in chondrichthyans: batoids. Brain Behav Evol 72:262-282.

Machold R, Fishell G (2005): Math1 is expressed in temporally discrete pools of cerebellar rhombic-lip neural progenitors. Neuron 48: $17-12$.

Meek J, Nieuwenhuys R (1998): Holosteans and teleosts; in Nieuwenhuys R, Donkelaar HJt, Nicholson C (eds): The Central Nervous System of Vertebrates. New York, NY, Springer, pp 759-937.

Montgomery JC (1980): Dogfish horizontal canal system: responses of primary afferent, vestibular, and cerebellar neurons to rotational stimulation. Neuroscience 5:17611769.
Montgomery JC (1982): Functional organization of dogfish vestibulo-cerebellum. Brain Behav Evol 20:118-128.

Montgomery JC (1983): Eye movement dynamics in the dogfish. J Exp Biol 105:297-303.

Montgomery JC (1984): Noise cancellation in the electrosensory system of the thornback ray: common mode rejection of input produced by the animal's own ventilatory movement. J Comp Physiol 155:103-111.

Montgomery JC, Bodznick D (1993): Hindbrain circuitry mediating common mode suppression of ventilatory reafference in the electrosensory system of the little skate, Raja erinacea. J Exp Biol 183:203-215.

Montgomery JC, Bodznick D (1994): An adaptive filter cancels self-induced noise in the electrosensory and lateral line mechanosensory systems of fish. Neurosci Lett 174:145148.

Montgomery JC, Coombs S, Conley RA, Bodznick D (1995): Hindbrain sensory processing in lateral line, electrosensory, and auditory systems: a comparative overview of anatomical and functional similarities. Aud Neurosci 1:207-231.

Montgomery JC, Bodznick D (2010): Functional origins of the vertebrate cerebellum from a sensory processing antecedent. Curr Zool 56:277-284.

Morita Y, Finger TE (1985): Reflex connections of the facial and vagal gustatory systems in the brainstem of the bullhead catfish, Ictalurus nebulosus. J Comp Neurol 231:547-558.

-Murakamia Y, Uchidab K, Rijlia FM, Kuratanib $S$ (2005): Evolution of the brain developmental plan: insights from agnathans. Devel Biol 280:249-259.

Myagkov NA (1991): The brain sizes of living Elasmobranchii as their organization level indicator. I. General Analysis. J Hinforsch 32:553-561.

New JG (2001): Comparative neurobiology of the elasmobranch cerebellum: theme and variations on a sensorimotor interface. Environ Biol Fish 60:93-108.

Nieuwenhuys R (1967): Comparative anatomy of olfactory centres and tracts; in Zotterman $\mathrm{Y}$ (ed): Progress in Brain Research. Amsterdam, Elsevier, vol 23, pp 1-64.

Northcutt RG (1977): Elasmobranch central nervous system organization and its possible evolutionary significance. Am Zool 17:411429.

Northcutt RG (1978): Brain organization in the cartilaginous fishes; in Hodgson ES, Mathewson RF (eds): Sensory Biology of Sharks, Skates, and Rays. Arlington, Office of Naval Research, pp 117-194.

Northcutt RG, Gans C (1983): The genesis of neural crest and epidermal placodes: A reinterpretation of vertebrate origins. Quarterly Rev Biol 58:1-28.

Northcutt RG (2002): Understanding vertebrate brain evolution. Integr Comp Biol 42:743756. 
Paul DH, Roberts BL (1979): The significance of cerebellar function for a reflex movement of the dogfish. J Comp Physiol 134:69-74.

Paul DH, Roberts BL (1984): The activity of cerebellar neurones of the decerebrate dogfish Scyliorhinus during spontaneous swimming movements. J Physiol 352:1-16.

Perks KE (2007): Adaptive sensory filtering in the cerebellar-like mechanosensory nucleus of the hindbrain in Raja erinacea; MA thesis, Wesleyan University Middletown, p 66.

Pollen AA, Dobberfuhl AP, Scace J, Igulu MM, Renn SCP, Shumway CA, Hofmann HA (2007): Environmental complexity and social organization sculpt the brain in Lake Tanganyikan cichlid fish. Brain Behav Evol 70:21-39.

- Porrill J, Dean P (2007): Cerebellar motor learning: when is cortical plasticity not enough? PLoS Comput Biol 3:1935-1950.

Puzdrowski RL, Leonard RB (1994): Vestibulooculomotor connections in an elasmobranch fish, the Atlantic stingray, Dasyatis sabina. J Comp Neurol 339:587-597.
Ronan M, Northcutt RG (1998): The central nervous system of hagfishes; in Jorgensen JM, Lomholt JP, Weber RE, Malte H (eds): The Biology of Hagfishes. London, Chapman \& Hall, pp 454-478.

Schmidt A, Bodznick D (1987): Afferent and efferent connections of the vestibulolateral cerebellum of the little skate, Raja erinacea. Brain Behav Evol 30:282-302.

Shumway CA (2010): The evolution of complex brains and behaviors in African cichlid fishes. Curr Zool 56:144-156.

Striedter GF (2005): Principles of Brain Evolution. Sunderland, Sinauer Associates.

Timerick SJB, Paul DH, Roberts BL (1990): Dynamic characteristics of vestibular-driven compensatory fin movements of the dogfish. Brain Res 516:318-321.

Wang VY, Rose MF, Zoghbi HY (2005): Math1 expression redefines the rhombic lip derivatives and reveals novel lineages within the brainstem and cerebellum. Neuron 48:3143.

Weigle C, Northcutt RG (1998): To the phylogenetic origin of the cerebellum: tracing studies on the Silver Lamprey Ichthyomyzon unicuspis. Eur J Neurosci 10:196.
Yopak KE, Lisney TJ, Collin SP, Montgomery JC (2007): Variation in brain organization and cerebellar foliation in chondrichthyans: sharks and holocephalans. Brain Behav Evol 69:280-300.

Yopak KE, Montgomery JC (2008): Brain organization and specialization in deep-sea chondrichthyans. Brain Behav Evol 71:287304

Yopak KE, Frank LR (2009): Brain size and brain organization of the Whale Shark, Rhincodon typus, using magnetic resonance imaging. Brain Behav Evol 74:121-142.

- Yopak KE, Lisney TJ, Darlington RB, Collin SP Montgomery JC, Finlay BL (2010a): A conserved pattern of brain scaling from sharks to primates. Proc Natl Acad Sci 107:1294612951.

Yopak KE, Ainsley SM, Ebert DA, Frank LR (2010b): Exploring adaptive evolution in the brains of bathyal skates (family: Rajidae): Phylogenetic and ecological perspectives. Brain Behav Evol 75:316.

Yopak KE (2012): Neuroecology in cartilaginous fishes: the functional implications of brain scaling. J Fish Biol 80:1968-2023. 